\title{
Occupational Safety and Health Aspects of Corporate Social Responsibility (CSR) in Japanese Companies Listed on the Tokyo Stock Exchange (TSE) First Section
}

\author{
Futoshi Kawashita $^{1}$, Yukari TaniYama ${ }^{1}$, Song You Hwi ${ }^{1}$, Takeshi Fujisaki ${ }^{1}$, Takashi Kameda ${ }^{1}$ \\ and Koji Mori ${ }^{1}$
}

${ }^{1}$ Occupational Health Training Center, University of Occupational and Environmental Health, Japan

\begin{abstract}
Occupational Safety and Health Aspects of Corporate Social Responsibility (CSR) in Japanese Companies listed on the Tokyo Stock Exchange (TSE) First Section: Futoshi KaWASHITA, et al. Occupational Health Training Center, University of Occupational and Environmental Health-Recently, corporate social responsibility (CSR) is becoming widely recognized as an issue for Japanese companies. Corporate responsibility for employees is considered important by various stakeholders, and occupational safety and health is regarded as one of these responsibilities. The present authors examined this issue from the viewpoint of corporate management by analysis of statements found in CSR-related reports. For companies listed on the First Section of the Tokyo Stock Exchange (TSE), we searched for CSR-related reports, and titles and contents, based on two established guidelines: the GRI Sustainability Reporting Guidelines 2002 as the international reference and the Environmental Reporting Guidelines of the Ministry of the Environment, Government of Japan, as the domestic reference. Corporations that published CSR reports were $26.3 \%$ $(416 / 1,581)$ of the total, and large differences were recognized by type of industry. Comparing the numbers of pages for various contents, more concern was shown about the environment than about social activity, indicating the environment to be the main issue of CSR in Japan. In the items included in the guidelines, many matters about occupational accidents were mentioned, but it was found that statements regarding HIV/AIDS, which is not of such strong social concern in Japan, and statements regarding the costs of safety that are difficult to calculate were few. However, statements
\end{abstract}

Received May 21, 2005; Accepted Aug 16, 2005

Correspondence to: F. Kawashita, Occupational Health Training Center, University of Occupational and Environmental Health, 11 Iseigaoka, Yahatanishi-ku, Kitakyushu 807-8555, Japan (e-mail:f-kawa@med.uoeh-u.ac.jp) regarding mental health, which is of high interest socially, were many, even though this issue is not included in the two guidelines used. In revising the guidelines, these matters should be reviewed. In the future, continuance of analysis of CSR-related reports with regard to changes and comparisons with overseas reports will help improve occupational safety and health.

(J Occup Health 2005; 47: 533-539)

Key words: Occupational safety and health, Corporate Social Responsibility (CSR), Global Reporting Initiative (GRI), Environmental Reporting Guidelines of the Ministry of the Environment, Companies listed on the Tokyo Stock Exchange, First Section

Recently, the concept of corporate social responsibility (CSR) as an issue for corporate management is becoming widely recognized by Japanese companies. This kind of thinking is a result the environmental pollution issues that arose in the 1970's ${ }^{1)}$. Corporate responsibility for the environment came to be widely recognized. A succession of serious incidents of corporate environmental pollution occurred and as a result, corporate culture and problems regarding the environment were better understood and led to the conclusion that corporate ethics made for good corporations. Corporations had to not only observe legislation but also become good social models ${ }^{2,3)}$.

Various stakeholders have an interest in a corporation ${ }^{4}$, and are subjects demanding ethical responsibility of a corporation involving the community, employees, legislation, consumers, etc., as well as the natural environment.

Thus responsibility for employees has become an important aspect of CSR. Human rights, discrimination, sexual harassment, whistle-blowing, wages ${ }^{5-8)}$ were previously essential for the employees of a corporation, but safety and health care of employees was left more or 
less up to the workers themselves.

Over the past several years, the number of corporations publishing CSR-related reports and showing these reports on internet homepages has rapidly increased. CSR requires not only action but also an explanation of the action, and managements' thinking regarding CSR have also begun to be recognized as an important aspect of CSR. This first began to appear in the form of environmental reports (including environmental conservation reports and environmental action reports) several years ago.

Moreover, various guidelines for corporations making such reports have been published domestically and internationally. For example, the Global Reporting Initiative (GRI) sustainability reporting guidelines $2002^{9)}$, GRI is supporting an independent institution whose mission is to develop and disseminate the globally applicable Sustainability Reporting Guidelines as one of the international guidelines. The Environmental Reporting Guideline published by the Ministry of the Environment, Government of Japan 2003 ${ }^{10)}$ (hereafter, guideline of the Ministry of the Environment) is a domestic guideline. In these guidelines, the items covered by CSR-related reports on environmental action and social activity are included and the contents described. Content regarding occupational safety and health is included.

Therefore, the authors decided to examine occupational safety and health from the view point of CSR in Japan by investigating and analyzing CSR-related reports issued by Japanese companies listed on the Tokyo Stock Exchange (TSE) First Section and comparing them with the above guidelines.

\section{Methods}

\section{Subjects}

The subjects of study were companies listed on the First Section of the TSE, excluding companies that had merged, as of November 1, 2004. These were taken from among the 1,581 TSE listed companies included in the Kaisha Shikihou, 2004 CD-ROM, which is a Japanese database of listed companies.

\section{Investigation period}

For this study, investigations were carried out in November 2004.

\section{Investigation method}

We searched homepages and conducted an investigation for the following items using PDF files and pamphlets, which were requested and obtained.

1) Publication of a CSR-related report and the name of the report

We searched for the publication of a report on homepages in 2004 for each company.

Each report was classified by its title into an environmental report (including environmental conservation reports and environmental action reports), environmental social report (including environment and social activity reports), social responsibility report and sustainability report (including CSR reports). We compiled an index to indicate the content of each report.

Furthermore we searched for the mentions of occupational safety and health.

2) The ratio of report contents (environment, society, occupational safety and health)

The contents of the reports were classified as environmental report contents, social activity contents and others. Content concerning occupational safety and health was included under social activity. We investigated the number of pages assigned to each content in the report of each company. Then, the number was divided by total pages to calculate the ratio of contents.

3) Description of occupational safety and health in the GRI guideline and the guideline of the Ministry of the Environment, Japan

We investigated six health and safety items (Table 2 ) in the GRI guidelines. However, with regard to occupational health management systems, we researched them as a description of occupational health management systems in this study because it was difficult to distinguish compliance with the ILO guidelines from other guidelines.

Table 1. Occupational Safety and Health in the GRI Sustainability Reporting Guidelines

- Practices on recording and notification of occupational accidents and disease, and how they relate to the ILO Code of Practice on Recording and Notification of Occupational Accidents and Diseases.

- Description of formal joint health and safety committees comprising management and worker representatives and proportion of workforce covered by any such committees.

- Standard injury lost days, and absentee rates and number of work-related fatalities (including subcontracted workers).

- Description of policies or programmes (for the workplace and beyond) on HIV/AIDS.

- Evidence of substantial compliance with the ILO Guidelines for Occupational Health Management Systems.

- Description of formal agreements with trade unions or other bona fide employee representatives covering health and safety at work and proportion of the workforce covered by any such agreements. 
Table 2. Occupational Safety and Health in the Environmental Reporting Guidelines by the Ministry of the Environment, Government of Japan

- Policy on health and safety, plan, description of an action.

- Occupational accident incidence, the number of occupational accidents.

- The frequency rate representing the number of work-related deaths and injuries per one million actual work-hours.

- Lost work days.

- The severity rate representing the total number of lost work days per one thousand actual work-hours.

- Costs affecting health and safety cost per worker.

Table 3. Companies listed on the First Section of the Tokyo Stock Exchange

\begin{tabular}{ccc}
\hline Classification of companies & Type of industry & The number of companies \\
\hline Primary industries & Fisheries, agriculture and foresry & 6 \\
\hline \multirow{2}{*}{ Secondary industries } & Mining & 6 \\
& Construction & 104 \\
& Manufacturing & 820 \\
\hline \multirow{2}{*}{ Tertiary industries } & Electricity and gas & 16 \\
& Transportation, information amd communication & 138 \\
& Commerce & 248 \\
& Finance and insurance & 139 \\
& Real estate & 37 \\
& Services & 67 \\
\hline
\end{tabular}

Items noted in the guidelines of the Ministry of the Environment (Table 3) were investigated in the same way.

4) Items not described in the two guidelines

Items not included in the GRI guidelines or in the guidelines of the Ministry of the Environment were researched.

\section{Results}

1. Publication of CSR-related reports, titles of the reports, and number of reports about occupational safety and health

The numbers of companies by type of industry (classified by the Securities Identification Code Committee in Japan) are shown in Table 1.

In addition, we classified the companies by primary, secondary and tertiary industry according to the Ministry of Economy, Trade and Industry of Japan. This classification is also shown.

For each of the 1,581 subject companies, we confirmed whether or not the company had a homepage. Among those with a homepage, the publication of a CSR-related report which could be read, on PDF file on the company's homepage or ordered in hard copy, was found for 416 $(26.3 \%)$ of the subject companies. By type of industry, electricity and gas published the most with 15 of 16 companies $(93.8 \%)$, followed by manufacturing, 310 of 820 companies $(37.8 \%)$. On the other hand, no reports were found companies listed under fisheries, agriculture, forestry and mining. As for the titles of the reports, numerous environmental reports were found, but environment, social reports and CSR sustainability reports were extremely few (Fig. 1). Descriptions of occupational safety and health were found in $215(13.6 \%)$ of all companies, representing $51.7 \%$ of the companies that had published reports (215/416).

Dividing the companies into primary, secondary and tertiary industries, we found that in the primary and secondary industries, descriptions about occupational safety and health were noted in reports from $186(19.9 \%)$ of 936 companies, representing 56.4\% (186/330) of all companies publishing reports. For the tertiary industries, descriptions on health and safety were found for $29(4.5 \%)$ of 645 companies, representing $33.7 \%$ (29/86) of those that had published reports.

Stratified by the number of employees, $82.7 \%$ (43/52) of the companies with more than 10,000 employees that had published CSR-related reports mentioned occupational safety and health. However, as the number of employees decreased, the percentage also decreased, 


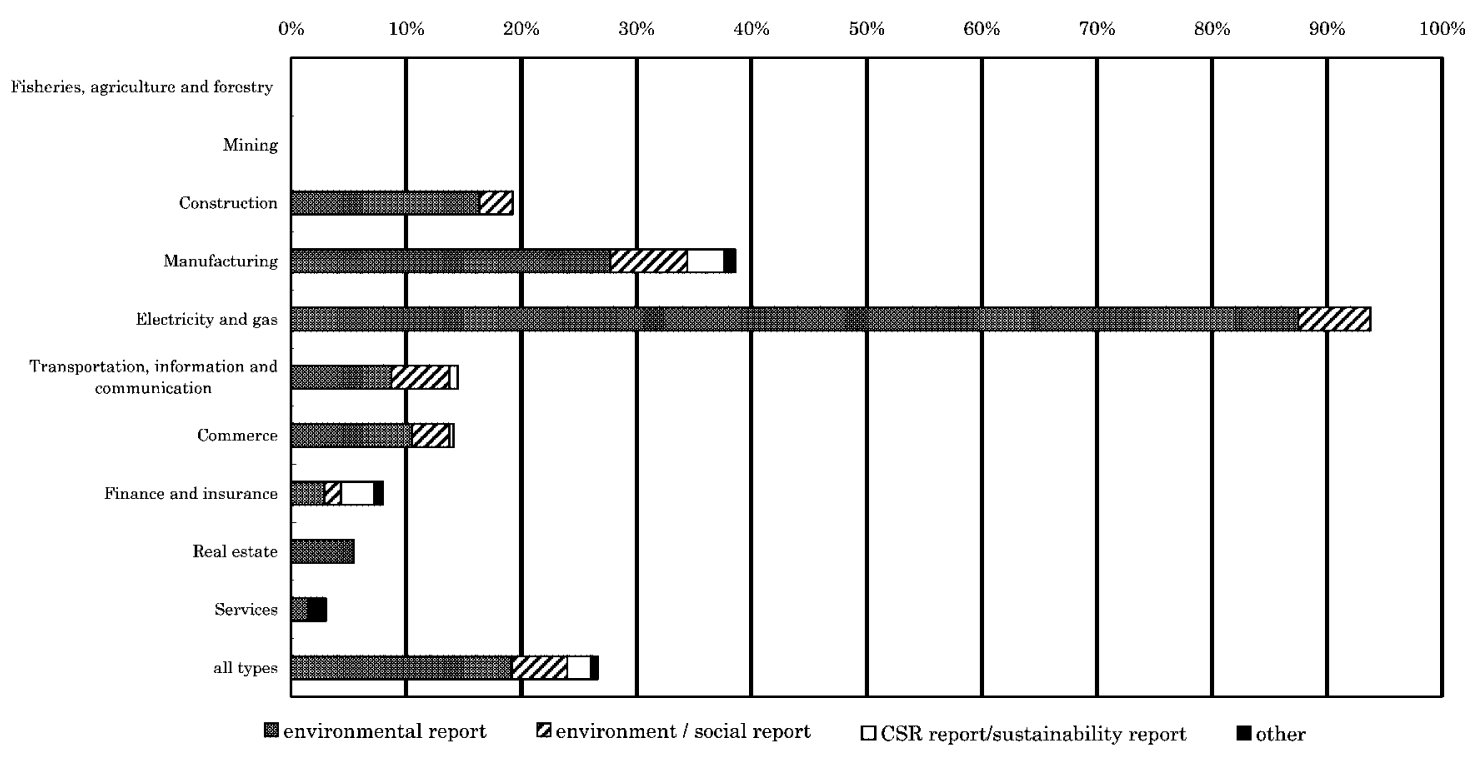

Fig. 1. Publication and the titles of CSR reports according to type of industry.

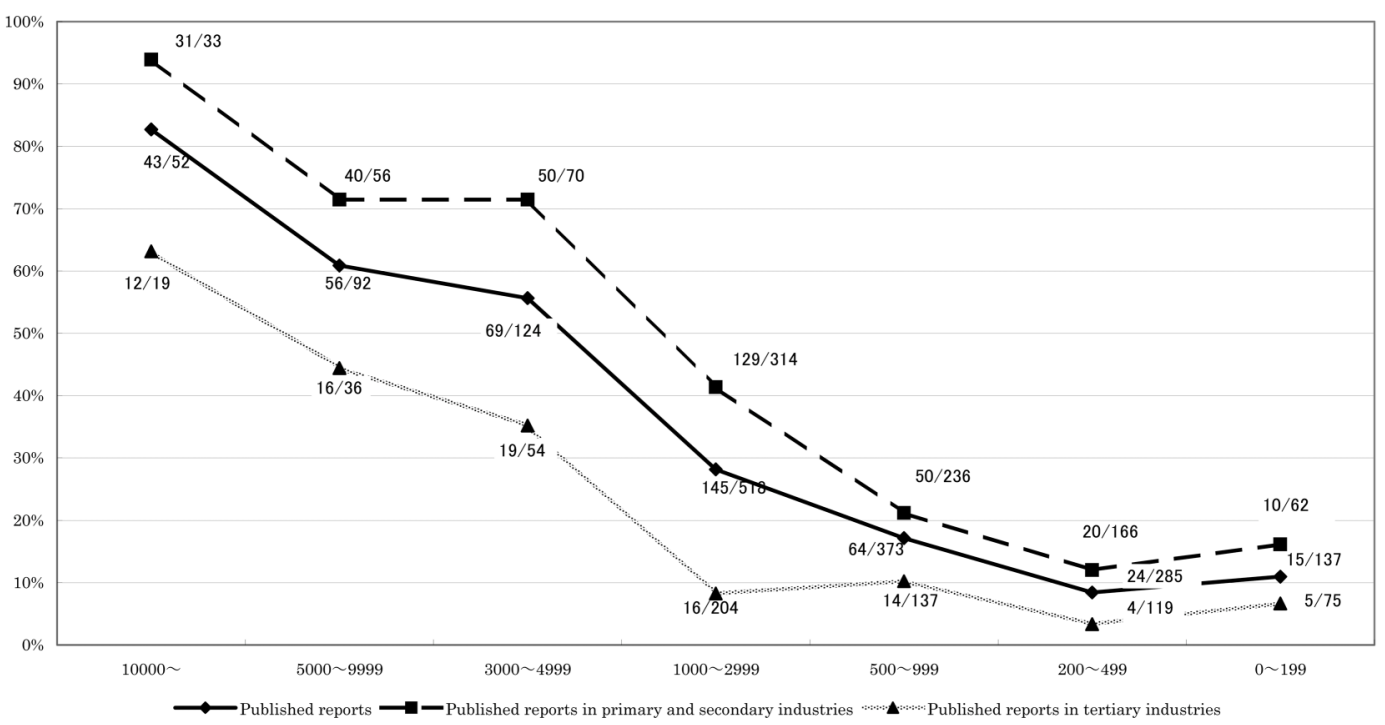

Fig. 2. Publication of CSR-related reports according to the number of employees.

being only $10.9 \%$ for those companies with employees numbering 0-199 (Fig. 2).

\section{Ratio of report contents (environment, society,} occupational safety and health)

The 416 companies that had published reports were reviewed. For all industries, $60.3 \%$ of report contents mentioned the environment, $16.8 \%$ mentioned society (not including occupational safety and health), and $1.7 \%$ mentioned occupational safety and health.

For categories of primary, secondary and tertiary industries, in the primary and secondary industries, $62.4 \%$ of report contents mentioned the environment, $14.7 \%$ society (not including occupational safety and health), and $2.0 \%$ mentioned occupational safety and health. In the tertiary industries, $55.6 \%$ of report contents mentioned the environment, $17.8 \%$ society (not including occupational safety and health), and $0.7 \%$ mentioned occupational safety and health (Fig. 3).

3. Description of occupational safety and health items in the GRI guidelines and the guidelines of the Ministry of the Environment, Japan

Regarding occupational safety and health contents in 


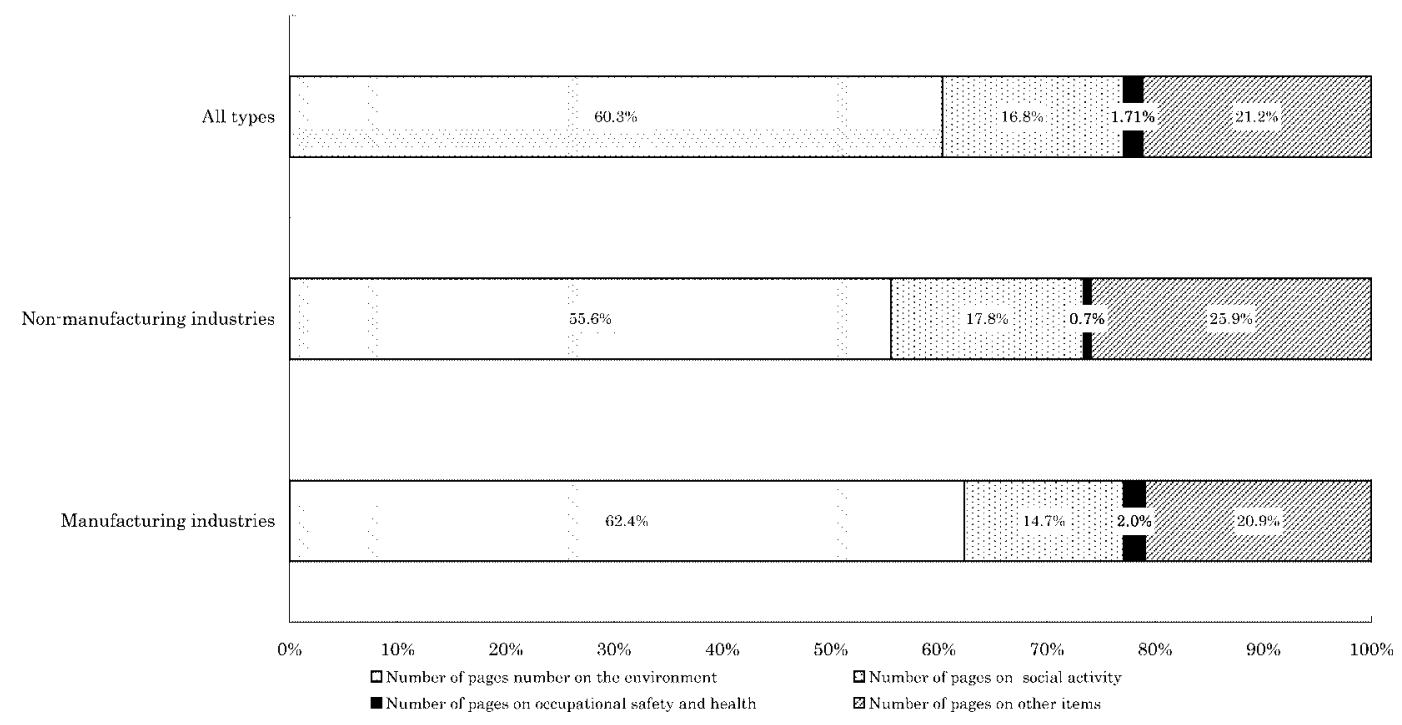

Fig. 3. Report contents (environment, social activity, occupational safety and health).

Table 4. Descriptions of occupational safety and health according to the GRI guidelines and the guidelines of the Ministry of the Environment, and topics not included in theguidelines.

\begin{tabular}{|c|c|c|c|c|c|c|c|}
\hline \multirow[t]{2}{*}{ Contents } & \multicolumn{2}{|c|}{$\begin{array}{l}\text { All types } \\
(\mathrm{n}=416)\end{array}$} & \multicolumn{2}{|c|}{$\begin{array}{l}\text { Primary and secondary } \\
\text { industries }(\mathrm{n}=330)\end{array}$} & \multicolumn{2}{|c|}{$\begin{array}{c}\text { Tertiary } \\
\text { industries }(\mathrm{n}=86)\end{array}$} & \multirow{2}{*}{$\begin{array}{l}p \text { value } \\
\left(\chi^{2} \text { test }\right)\end{array}$} \\
\hline & $\mathrm{n}$ & $\%$ & $\mathrm{n}$ & $\%$ & $\mathrm{n}$ & $\%$ & \\
\hline \multicolumn{8}{|l|}{ GRI guidelines } \\
\hline Occupational accidents & 136 & $32.7 \%$ & 128 & $38.8 \%$ & 8 & $9.30 \%$ & $*$ \\
\hline Health and safety committees & 44 & $10.6 \%$ & 34 & $10.3 \%$ & 10 & $11.6 \%$ & \\
\hline Standard injury & 8 & $1.9 \%$ & 7 & $2.1 \%$ & 1 & $1.2 \%$ & \\
\hline HIV/AIDS & 4 & $1.0 \%$ & 3 & $0.9 \%$ & 1 & $1.2 \%$ & \\
\hline OSHMS & 46 & $11.1 \%$ & 41 & $12.4 \%$ & 5 & $3.5 \%$ & \\
\hline Trade union & 9 & $2.2 \%$ & 7 & $2.1 \%$ & 2 & $2.3 \%$ & \\
\hline \multicolumn{8}{|l|}{ Guidelines of the Ministry of the } \\
\hline \multicolumn{8}{|l|}{ Environment government } \\
\hline Policy, plan etc. & 170 & $40.9 \%$ & 156 & $47.3 \%$ & 14 & $16.3 \%$ & * \\
\hline Occupational accidents & 139 & $33.4 \%$ & 127 & $38.5 \%$ & 12 & $14.0 \%$ & $*$ \\
\hline Frequency rate & 111 & $26.7 \%$ & 104 & $31.5 \%$ & 7 & $8.1 \%$ & $*$ \\
\hline Lost work days & 3 & $0.7 \%$ & 3 & $0.9 \%$ & 0 & $0.0 \%$ & \\
\hline Severity rate & 44 & $10.6 \%$ & 42 & $12.7 \%$ & 2 & $2.3 \%$ & $*$ \\
\hline Costs & 32 & $7.7 \%$ & 29 & $8.8 \%$ & 3 & $3.5 \%$ & \\
\hline \multicolumn{8}{|l|}{ Not included in the guidelines } \\
\hline Mental health & 133 & $32.0 \%$ & 110 & $33.3 \%$ & 23 & $26.7 \%$ & \\
\hline Road safety & 15 & $3.6 \%$ & 10 & $3.0 \%$ & 5 & $5.8 \%$ & \\
\hline Smoking & 24 & $5.8 \%$ & 17 & $5.2 \%$ & 7 & $8.1 \%$ & \\
\hline Health promotion & 46 & $11.1 \%$ & 36 & $10.9 \%$ & 10 & $11.6 \%$ & \\
\hline Others & 18 & $4.3 \%$ & 13 & $3.9 \%$ & 5 & $5.8 \%$ & \\
\hline
\end{tabular}

the reports, e.g., policies about health and safety, a plan, or description of an action, many companies describe these as a purpose of action in $40.9 \%$ of all reports. Descriptions about occupational accidents mentioned in both guidelines were found in 10.6-32.7\% of all reports. Descriptions regarding health and safety committees were found in $10.6 \%$, a comparatively high frequency. However, for standard injury lost days, HIV/AIDS, lost 
Table 5. Statements relating to mental health by primary, secondary and tertiary industries

\begin{tabular}{lccr}
\hline & Mental health (+) & Mental health (-) & \\
\hline Primary, secondary industries & 111 & 75 & 186 \\
Tertiary industries & 23 & 6 & 29 \\
& 134 & 81 & 215 \\
\hline
\end{tabular}

$\chi^{2}$ test $p$ value $<0.05$

work days, and costs, the description rate in the reports that mentioned occupational safety and health in CSRrelated reports was low, less than $10 \%$.

\section{Items not included in the GRI or Ministry of Environment guidelines}

There were some items mentioned that were not included in the GRI or Ministry of Environment guidelines, e.g., mental health, road safety, smoking (cessation of smoking), and health promotion (Table 4). Thirty-two percent of the companies publishing CSRrelated reports particularly mentioned mental health. Of these $26.7 \%$ were in the tertiary industries, $33.3 \%$ in the primary and secondary industries (Table 4 ). In addition, of the number of the companies which reported on occupational safety and health, 79.3\% (23/29) were in the tertiary industries and $59.7 \%(111 / 186)$ in the primary and secondary industries, i.e., the tertiary industries showed a higher rate $\left(\chi^{2}\right.$ test $p$ value $\left.<0.05\right)$ (Table 5). Regarding mental health, stress, employee education, manager education, office counseling, and concerns outside the company were mentioned. These issues are equivalent to four points in the guidelines for the mental health of the workers established by the Ministry of Health, Labour and Welfare of Japan ${ }^{11)}$.

\section{Discussion}

In this study, we analyzed corporations' intentions for the liability of explanation of action by the publication, what the important items are in CSR-related reports as a percentage of contents, and what the important items are in occupational safety and health by their description. To our knowledge, there are no papers that had analyzed occupational safety and heath descriptions in CSR-related reports, except for CSR in the tobacco industry ${ }^{12)}$ published.

The present study found that the highest percentage of CSR-related reports were published by the gas and electric companies, manufacturers and large-scale corporations with large numbers of employees. Many of these discussed environmental issues and/or were widely involved in general society. Approximately quarter of the companies in the study published reports in 2004.

We interpreted the titles of CSR-related reports as standing for important matters in the reports. Report contents indicated what corporations should explain actions. Many reports were concerned with environmental issues. We consider this is the result of CSR action having been instigated by environmental protection issues. However, corporations have gradually begun to recognize stakeholders including the community, employees and environmentalists. Corporate responsibility for the safety and health of stakeholders such as its employees has come to be considered important by management and about half the corporations publishing CSR-related reports wrote about occupational safety and health ${ }^{13)}$. Thus the role of occupational health professionals in CSR action has become more important than ever.

Various guidelines for CSR-related report-making have been published domestically and internationally, but these guidelines are not considered to be appropriate for all corporations in all countries, areas and types of industry. There is a need to specify future revisions for analyzing report contents.

In this study, based on the GRI and Ministry of Environment guidelines, many corporations noted occupational accidents under occupational safety and health in CSR-related reports, but descriptions of problems which are not of strong social interest in Japan, e.g., HIV/AIDS ${ }^{14)}$ and costs affecting health and safety, which are difficult to calculate are rare. In both the Ministry and GRI guidelines, items concerning occupational accidents and safety and health committees are listed, but mental health and other important items are not.

Mental health was mentioned by many companies and this requires attention. In Japan, the number of suicides has been increasing over the past several years ${ }^{15)}$, giving rise to interest in mental health by society and corporations. Thus, even though mental health was not included in the guidelines, CSR-related reports often included statements regarding the mental health of employees. In CSR-related reports mentioning occupational safety and health, the tertiary industries showed a higher rate of statements regarding the mental health than the primary and secondary industries, but the description rate was high even in the primary and secondary industries. Thus, in all three classifications of industry, primary, secondary and tertiary, problems 
regarding mental health were of high interest. The primary and secondary industries may have noted many problems regarding occupational safety and health as well as mental health, or the tertiary industries may have regarded mental health as more important than the primary and secondary industries.

The Chief Executive Officer (CEO) of each company reviewed signed the CSR-related report. According, we think the hypothesis that this makes it reasonable to assume the contents regarding occupational safety and health found in the reports express the ideas and opinions of management. Analysis of CSR reports is considered to be an index of corporate intentions. Because CSR is regarded as an important indicator of company action and social condition ${ }^{3)}$, in the future investigation and analysis of the publication rate of such reports, comparisons with those of foreign countries, and the degree of company intentions reflected in the reports should be conducted.

\section{References}

1) J Miyasaka: Environmental ethics studies and business ethics. Ind Economy. The second Vol.: 19 (2004)

2) P Khunaphante and L Sharp Paine: "The Siam Cement Group: Corporate Philosophy (B)" , HBS Case No.9398-019.

3) L Sharp Paine. Value Shift. New York: The McGrawHill Companies, Inc, 2003.

4) J Kaler. Morality and Strategy in Stakeholder Identification. J Business Ethics 39, 1-2 (2002)
5) PJ Borowski: Manager-Employee Relationship. Guided by Kant's Categorical Imperative or by Dilbert's Business Principle. J Business Ethics 17, 15 (1998)

6) M Booker : Can Sexual Harassment Be Salvaged? J Business Ethics 17, 11 (1998)

7) J Keyton and S Rhodes: Sexual Harassment: A Matter of Individual Ethics. Legal Definitions, or Organizational Policy. J Business Ethics 16, 2 (1997)

8) W Waluchow: Pay Equity. Equal Value to Whom? J Business Ethics 7 (1988)

9) GRI (Global Reporting Initiative) GRI Sustainability Reporting Guidelines 2002.

10) Environmental Reporting Guideline by the Ministry of the Environment Government of Japan (2003 version) March, 2004.

11) Ministry of Health, Labour and Welfare Labor Standards Bureau Occupational Safety and Health Department "Guideline for the making of cardiac health of a worker in business ground" August, 2000

12) N Hirschhorn: Related Articles, Corporate social responsibility and the tobacco industry: hope or hype? Tob Control 13, 447-453 (2004)

13) M Harrison: Beyond the fence line: corporate social responsibility. Clin Occup Environ Med 4, 1-8 (2004)

14) Kihara M: Socio-Epidemiological Studies on Monitoring and Prevention. Public welfare labor science research expense subsidy AIDS measures research business. March, 2003.

15) National Police Agency of Japan. Suicide statistical material. June, 2004. 